\title{
Reviewing the Role of Netnographic Research in Bridging the Gap between Youngsters and Adults
}

\author{
Sarnou Dalal* \\ Department of English Studies, University of Abdelhamid, Mostaganem, Algeria
}

Submission: December 15, 2018; Published: January 04, 2019

*Corresponding author: Sarnou Dalal, Faculty of Foreign Languages, Department of English Studies, University of Abdelhamid, Mostaganem, 33 Salem Said Oran, Algeria

\begin{abstract}
Either referred to as the information age, computer age or most commonly now as the digital age, this era of an unprecedented technological advancement in all fields has captured the attention of scholars in the humanities to investigate the ubiquitous nature of computing and the prolific use of technology in almost all aspects of human activity. Because the last two decades or so have been characterized by communication based on information technologies, a myriad of researches studying the very nature of human interaction with and through new technologies has escalated. Aiming at redefining humanity in the digital age, many scholars have brought about new theorizations that seek to answer questions like: do we shape technology or is it technology that shapes us? Donna Haraway's Cyborg theory (1991), for instance, proposes an imaginary world of fusions between animal and machine. Rosi Braidotti's the Posthuman Project (2012) explains that in the era of advanced postmodernity, the notion of 'the human' is both de-stabilized by technologically mediated social relations in a globally connected world and is thrown open to contradictory redefinitions of what is to be human.
\end{abstract}

By putting emphasis on the deeply-rooted changes that are happening to humanity at a high pace, the present paper reflects on new directions in the humanities that seek to decipher these technology-related changes. More particularly, my focus is to consider how Robert Kozinets' netnography, as an emerging research method in digital anthropology, can help educators, parents and students to understand the transformations that are taking place in their behavior in real life situations. By accentuating the strong impact spending long hours on social media and being glued to one's electronic devices have on our social behavior, I inquire, in this article, about the role netnographers could play in assisting teachers and parents to bridge the gap between the latter and youngsters by explaining to them the behavior of their students/ children who have become virtualized.

Keywords: Netnography; Social media; Virtual communities; New technologies; Education; Youngsters; Social media

\section{Introduction}

The world of internet is such a complex and dynamic environment. Not only the rise of the Internet has brought radical changes to the way we live, but also it has alarmed social sciences researchers to think about how online communication affects social relationships. Because the Internet is the tool people use to interact with one another, it accordingly poses new challenges to human relationships, privacy and security. In this sense, the Internet has changed business, education, government, healthcare, and even the ways in which we interact with our loved ones-it has become one of the key drivers of social evolution.

Therefore, in a growing digital world where billions of people around the globe are being absorbed by the magic of the virtual spaces, their multimedia and the boundless mobility they offer, old schools in the humanities have been alarmed by the rapid and uncontrolled change that made it ridiculous for researchers to investigate Man-related phenomena and issues in the same way they used to do few decades ago. Most of, if not all, disciplines, branches and sub-branches in the humanities have been coupled with the adjective 'digital' so that new disciplines are founded to respond to a world that is tremendously digitalized mostly in its Northern part (Japan, Europe and North America). One can now google the word 'digital' and add it to any discipline: linguistics, sociology, anthropology, ethnography, education, politics, literature, etc. So, new sub-branches have forcibly come of age to reflect the deep-rooted infiltration of new technologies and internet into the smallest aspects of humans' life.

More speedily than ever, humanity has been digitalized and/ or digitized due to the merging of new media technologies into every single angle of people's daily life. This has led contemporary scholars to ask a long list of questions, but the most significant of their inquiries is to closely inspect how our humanness is/ will be expressed in a world shaped by algorithms and bordered with virtual frontiers. An interesting emerging area of research is 'netnography' which is different from digital ethnography as it will be explained further in the following sections. The term 
'netnography' was first coined by Robert Kozinets in 1995 to refer to the online research method which originates in ethnography but is applied to understanding social interactions in contemporary digital communications contexts. According to Kozinets [1], netnography can be defined as a specific set of research practices related to data collection, analysis, research ethics, and representation, rooted in participant observation. So, it is an interpretive research method that adapts the traditional, in-person participant observation techniques of anthropology to the study of interactions and experiences manifesting through digital communications [1].

Questioning the significance of this emerging area in a digital age where millions of people spend much of their daily life online, this article aims at emphasizing the relevance of 'netnography' intersection with other studies related to education from primary to high school. A major concern would be what benefits netnography could offer to teachers, educators, parents and students themselves. By reflecting on the idea that netnography compiles and analyzes data about the free social behavior of individuals on the Internet, and that most of internet users are teenagers and younger people, I suggest that researches in this new field of expertise should be directed also to analyzing the behavior of young cybernauts, more specifically with the aim of understanding their behavior when they are online and how this would deeply affect their behavior when they go offline.

The starting point of my reflection on to what extent netnography could be helpful to understand the behavior of students and young people was that, according to Kozinets, netnography was initially founded to analyze the free behavior of individuals on the Internet and it uses online marketing research techniques to provide useful insights. Re-thinking the role this new discipline could play in fields other than marketing and digital studies, the educational realm must also be added to the list of areas of interest of netnographers. For this reason, the present article puts forward the idea of bringing netnographers, educators, parents and learners together to bridge the many technology-based gaps that are distancing older generations from youngsters, particularly in developing countries and countries where religion and traditions still manipulate people's life. In these countries and their societies, older people are still strongly attached to traditional lifestyles, and therefore consider young people as freak, weird and rebellious. This, I argue, causes a clash between older generations and youngsters because the former cannot understand the technology-driven life young people are immersed in and which is different from the life of older people of ten or more years ago.

To begin with, the following section gives an overview of how this area emerged, has recently burgeoned and is rapidly mushrooming. It first introduces digital humanities as a wider field of research whose development has inspired netnographers, and then it explains how digital anthropology as a new field must also be employed in educational studies since ethnography is the methodological chimera of anthropology, and so are digital anthropology and netnography.

Digital Humanities, Digital Anthropology and Netnography: The New Disciplines of the Digital Age

Before giving an overall description of what netnography -which is sometimes referred to as digital/ virtual ethnography -is, it is necessary to understand how digital humanities as a wider field of research emerged and expanded. So digital humanities (henceforth DH) is described as the new technology-driven academic field concerned with the application of computational tools and methods to traditional humanities disciplines such as literature, history, and philosophy.

Also termed as 'humanities computing', the editors of a companion to Digital Humanities who introduced the term abruptly in 2004 as an expansion of what was commonly referred to as Humanities Computing, argue that the field 'redefined itself to embrace the full range of multimedia' [2]. In his book The Emergence of Digital Humanities, Steven E. Jones explains that as a new model, DH emerged more or less concurrently with the new context associated with the new developments in technology [mobile technologies, web 2.0, social media, etc] the term digital humanities itself was solidified in a collection of essays published online in 2004 (reference sited previously) and a hardcover book in 2005 Blackwell's Companion to Digital Humanities [3]. Jones adds that even that term, field of study, should be thought of as a field or an (inter)discipline or just a label of convenience for the moment for what all humanists will be doing relatively soon (p5).

Not accurately and fully defined so far, DH can be understood as an umbrella term for a diverse set of practices and concerns, all of which join computing and digital media with humanities research and its teaching. Therefore, instead of a definition, Rafael Alvarado argues that we have a genealogy, a network of family resemblances among provisional schools of thought, methodological interests, and preferred tools, a history of people who have chosen to call themselves digital humanists and who in the process of trying to define the term are creating that definition [4]. Therefore, Alvarado calls Digital Humanities a social category, not an ontological one. He is supported by Matt Kirschenbaum, who defined Digital Humanities in the 2011 Day of Digital Humanities survey as 'a term of tactical convenience' [5]. Kirschenbaum in his essay 'What Is Digital Humanities and What's It Doing in English Departments?' [6] reminds us that the affirmation of Digital Humanities as the common name for the field was facilitated by the publication of A Companion to Digital Humanities in 2004.

For the moment, we know that Digital Humanities tries to model the world around us through success and failure in order to arrive at a better understanding of what we know and do not know about humankind, their activities, artifacts, and record. And this may serve as a definition of the field [7]. On 
another hand, the increasing digital intervention in the field of anthropological inquiry is indisputable. Rather than denying the infiltration of the digital/virtual world into the real-life practices, anthropologists are giving significant considerations to software as infrastructure and materiality at the sites of their research. They are also becoming more aware of their own digital research practices as they, themselves, utilize digital technology to organize, manage, and publish their field findings.

From that perspective, we understand that digital anthropology, as another emerging field, was founded to respond to the adjustments brought about by anthropologists to their field of research to cope with the deep infiltration of new media technologies and advancements in human's life. The core tenet of digital anthropology is that we can no longer treat the virtual and the physical as distinct or separate. In fact, it is worth noting that digital anthropology is considered by some researchers as distinct from cyber-anthropology. To put this idea into perspective, the Colombian-American anthropologist Arturo Escobar with his article "Welcome to Cyberia: notes on the anthropology of cyberculture" in Current Anthropology, did use the concept of "cyberculture" to analyze fundamental transformations in the structure and meaning of "modern" society and culture due to computer information, and biological technologies. He argues: "as a new domain of anthropological practice, the study of cyberculture is particularly concerned with the cultural construction and reconstruction on which the new technologies are based and which they in turn help to shape" [8]. So, for Escobar [8] the study of cyberculture refers particularly to new technologies in two areas: computer and information technologies, including artificial intelligence, and biotechnologies, including genetic engineering. The first are bringing about a regime of techno-sociality, a process of socio-cultural construction activated by the new technologies. Biotechnologies, on the other hand, "are giving rise to biosociality, a new order for the production of life, nature and the body" [8].

Therefore, one can argue that cyber-anthropology is concerned with new technologies and how they are constructed, implemented and utilized in society and culture. In this respect, cyber-anthropology is not something completely new. Since the 1950s, anthropologists have been studying new and modern technologies and their impact on, particularly non-western, societies to an increasing degree $[9,10]$.

Identified by professor Philipp Budka from University of Vienna as distinct from cyber-anthropology, digital anthropology, as a sub-discipline, is the study of the consequences of the rise of digital technologies for populations, the use of these technologies within anthropological methodology, or the study of specific digital technologies. More specifically, the study of digital anthropology has already gone through several iterations. An earlier review concentrated on the exploration of online communities [11], while a later review focused more on the ethnographic approach to digital media. A more recent edited collection [12] examined the variety of fields of study, ranging from location to politics to domestic life, as well as the implications for theory and anthropology more generally. Daniel Miller, a pioneer in the study of digital anthropology and especially ethnographic research on the use and consequences of social media and smartphones as part of the everyday life of ordinary people around the world, elucidates that digital anthropology has to contend with the way culture itself has grown in scale and form, including new dreams and new nightmares about who we are becoming, and who or what should be regarded as modern or traditional. For the anthropologist, the digital is always approached in context [13].

Therefore, and because digital anthropology is primarily concerned with how people interact in the virtual space, new methodologies and techniques should be innovated to successfully contextualize studies of human behavior in the virtual space. This space, one should emphasize, is not a static environment. It is, rather, a world in which we need to know how to research in it as it develops and changes. As such, digital environments are re-defining ethnographic practice. As new technologies offer new ways of engaging with emergent research environments, actual practices of anthropologists do shift accordingly. One way of doing anthropological research on and in virtual environments is to do it via ethnographical methods. Also, it is interesting to note that most of the attempts to define ethnography as 'digital' have been focused in anthropology and sociology.

In fact, the increasing digital intervention in the field of ethnographic inquiry is undeniable, and if the role of ethnographers is to examine human interactions, expressions, and other cultural processes, this role must adapt to the radical changes social life is witnessing. One way of re-orienting research interests of ethnographers was through innovating new research methods as it is the case with digital ethnography and netnography. For the latter, it is a relatively new research method, which adapts research techniques of ethnography to study of cultures and communities through computer-mediated communications.

The term netnography is a portmanteau combining "Internet" or "network" with "ethnography". Netnography was originally developed in 1995 by marketing professor Robert Kozinets as a tool to analyze online fan discussions about the Star Trek franchise. The use of the method spread from marketing research and consumer research to a range of other disciplines, including education, library and information sciences, hospitality, tourism, computer science, psychology, sociology, anthropology, geography, urban studies, leisure and game studies, and human sexuality and addiction research.

Netnography is widely employed as a research method in many disciplines and research fields such as information systems [14], marketing [15], and tourism [16]. In fact, using netnography 
as a research method has grown more popular in such areas of research. In 2002, Kozinets [17] defined four principles which should be followed when conducting netnographic research. These principles are: 1. a researcher should fully disclose his or her presence to the online community members which he or she is studying. 2. the researcher should guarantee the confidentiality and anonymity of the informants. 3. the researcher should seek and incorporate feedback from the online community members. 4. the researcher should ask community member's permission to directly quote any specific posting. For the last point, however, in 2010, Kozinets [18] acknowledged that it could be ethically just to study some online communities without asking permission to study them. In the next section, a short description of main netnographic research method principles will be discussed.

\section{About the Netnographic Research Method}

The virtual world is deemed to be more complex to understand and investigate than real life contexts. Therefore, in doing research on and in internet, many data collecting methods have been used and innovated, both quantitative and qualitative. However, the quantitative surveys are often the most used method. More precisely, there are two major methodologies for collecting data through surveys in a virtual world: the avatar managed by the researcher invites random or specific avatars to participate in the research and then apply the survey; the other hypothesis is to apply the survey through bots [19]. Amongst the qualitative ones, ethnography has been the most used. Due to its social character, the internet has allowed the emergence of virtual cultures and the ethnographic method "can therefore be used to develop an enriched sense of the meanings of the technology and the cultures which enable it and are enabled by it" [20]. A variety of terms are used for ethnographic approaches to online or digitally focused studies, from online and virtual ethnography to netnography (Hine 2017), but it appears that uncertainty over their use is common [21]. However, among the ethnographic methods, virtual ethnography and netnography are the most used.

Because millions of people around the globe are now using online communities such as Facebook groups, newsgroups, blogs, vlogs, forums and a lot of social networking sites, the virtual world has now become an important field for research. For anthropologists and ethnographers, it has become quite compulsory and unavoidable to do research on and with the internet, but how does one do ethnography of the Internet? In fact, the basic tenet in traditional anthropology is to step "off the veranda" to experience life from the informants' point of view, and this has long offered a new holistic approach to studying society. However, is it possible to transfer this same approach to studying how social interactions manifest themselves online?

In fact, virtual spaces, and social media, are often accessed by researchers to observe the participant in their natural environment. The online environment often compromises text, images or videos and is the host to social interactions and behavior patterns. For example, social media platforms, like Facebook and Twitter, are common digital spaces which researchers' access with the objective of observing how particular groups of internet users interact and behave.

Subsequently, it is argued by contemporary anthropologists (Miller and Horst) that internet-based social media must be studied as part of unbounded, yet locally specific social spaces. From this perspective, using netnography as a research method to understand social interactions in the virtual world is opted for by many researchers in many fields: sociology, anthropology, cultural studies, etc. As a "specialized form of ethnography" adapted to the Internet, netnography might be one of the most viable methods to use when internet-related phenomena are studied.

According to Kozinets, the foundation of netnography is rather simple. It is grounded by the principle that the perspective of an embodied, temporally, historically and culturally situated human being with anthropological training is, for purposes relating to identity, language, ritual, imagery, symbolism, subculture and many other elements that require cultural understanding, a far better analyst of people's contemporary online experience than a disembodied algorithm programmed by statistics and marketing research scientists.

According to the study conducted by Bengry-Howell et al. [22] on innovation and social research methods, netnography is among the exemplary innovative methods developed within qualitative research. In order to be considered an exemplar case study, the methodologies should facilitate the study of a new area of social life; provide an understanding of the aspects of social life that are difficult to access through traditional methods; and deal with ethical, access or response issues raised by traditional approaches, this was what netnography was estimated to do.

On another hand, Kozinets argues that the netnographic approach is adapted to help the researcher study not only forums, chat, and newsgroups but also blogs, audiovisual, photographic, and podcasting communities, virtual worlds, networked game players, mobile communities, and social networking sites [23]. The netnographic method is based on traditional participantobservation ethnographic procedures. It is conducted in six overlapping steps, like the stages of ethnographic research: developing a research plan, establishing entrée, collecting and triangulating data, analyzing and interpreting data, ensuring ethical standards, and reporting on research finding and associated insights. So, to conduct a netnographic research, these are the main steps: research plan, entrée, data collection, data analysis, and presentation then discussion of the results. The first step includes setting the goals, choosing the research object, and defining the research question. The entrée implies the identification of the community that will be studied, and the 'entrance' into that community. Then the researcher needs to select suitable methods for his qualitative analysis. 
As for the data that the netnographer collects from his/her observation of a given virtual environment, Ferreira explains that there are three types of data one can collect: archival data (data produced by the members of the community), elicited data (resulting from the interaction between the researcher and the members of the culture under analysis), and fieldnote data (resulting from the experiences lived by the researcher). The fourth stage is data analysis; the researcher should decide what technique is the most appropriate to analyze the collected data. And the fifth, and last, step concerns the presentation and discussion of the results.

In netnography, a significant amount of the data originates in and manifests through the digital traces of naturally occurring public conversations recorded by contemporary communications networks. Netnography uses these conversations as data. It is an interpretive research method that adapts the traditional, inperson participant observation techniques of anthropology to the study of interactions and experiences manifesting through digital communications. Though netnography is developed from ethnography and applied in the online settings, it is more than the application of qualitative research in the form of traditional ethnographic techniques in an online context. There are several characters that differentiate Netnography from Ethnography. Netnographic research is more focused on reflections and data provided by online communities, whereas ethnography can focus on the entire human society. Ethnography comprises research into all forms of human communication, including body language and tone of voice. Netnography incorporates human online communication, which is textual communication, or some multimedia communication such as video, audio, pictures. Netnography offers a less intrusive research experience than ethnography, because netnography uses mainly observational data.

In a same vein, it is argued that the main advantage of the netnography is that participants - or what I may call 'net formants' to refer to virtual informants -reveal information, also sensitive details, unasked and voluntarily online naturally, and therefore the netnographer could gain this organic information through observation. Compared with traditional ethnography which requires researchers to physically immerse into the samples to collect data, netnography allows the researcher to be able to download communication data directly from an online community. In this sense, netnographic researchers do not become members of communities and cultures as in traditional ethnographic practice, but rather are engaged in various and flexible levels of committed and public online social interaction thus immerse oneself in the community. I foresee that netnographers would play a significant role in bridging the gap between young teenagers, their teachers and parents. In what follows, I will explain how netnography can give an insight into the unexplored and unfamiliar behavior of young people who live as avatars in the virtual world and as marginalized human beings in real life, mainly in conservative societies.

\section{A Netnographic Exploration of Youngsters' Life as Socio-Virtual Beings}

In this concluding section, the aim is to draw the readers' attention to first re-think the way extensive use of new technologies and internet affects young people's behavior, and then to shape how netnographers could contribute to understanding and interpreting this behavior in order to narrow down the gap between teenagers and adults, and to reduce the tension that is mounting and affecting many social relationships: students-teacher relationship, parents-children relationship, and friendship. Zemmels [24] states that in today's postmodern (and post-human) society, the media have become as important as food and clothing. It plays a significant role in 'informing' a society and notably our current generation of children as young people spend more time with media than engaged in other activity. An important fact about today's young people worldwide is that they spend most of their time surfing the net, connecting with their friends on social media sites, playing video games or listening to music and watching videos. This makes them live a double life, and this often leads to a constant feeling of bewilderment, estrangement and alienation in their real-life communities, but at the same time these teenagers have a strong feeling of belongingness to virtual communities.

According to Maslow [25], after the physiological needs and the needs for survival and for safety and security have been met, the individual can be motivated to meet the needs represented at higher levels of the pyramid. These are the needs associated with love and belonging. These desires are met through satisfactory relationships - relationships with family members, friends, peers, classmates, teachers, and other people with whom individuals interact. Satisfactory relationships imply acceptance by others. However, with the emergence of the Internet, individuals are given an entirely new stage on which to live their lives, and diverse communities -virtual communities -to belong to. This new environment is quite different from that of the world observed by Maslow as he had developed his hierarchy of needs back in the twentieth century. Nowadays, virtual environments allow individuals to explore facets of their personality that they would be timid to reveal in less anonymous circumstances. The world of internet allows people, mainly youngsters, to build hundreds of new relationships but in a cyberspace, and this makes these relationships affect young people in a different way from what was revealed in Maslow's theory.

In fact, most young people go online to communicate with friends and e-friends and even anonymous people. This virtual communication is an important foundation of social relationships though the latter are not based on face-to-face conversations and contact. Most of the communications that people have online are on social networks, and particularly and mostly on Facebook, be it the most popular of all social media websites. One important feature of these communications is that they are virtual interactions. Sherry Turkle, a psychologist 
and expert on the social effects of virtual communication, writes the following in the introduction to her book, Alone Together: why we expect more from technology and less from each other (2011): As we distribute ourselves, we may abandon ourselves. Sometimes people experience no sense of having communicated after hours of connection. And they report feelings of closeness when they are paying little attention. In all of this, there is a nagging question: Does virtual intimacy degrade our experience of the other kind and, indeed, of all encounters, of any kind?

Turkle's words reveal that the many relationships one can build online may make this person feel lonely. In the same vein, and according to many contemporary psychologists, one of the most worrying features of social media is that it allows its users to become different people. This is worsened when the user is a teenager since adolescence is seen primarily as a state of transition, a matter of 'becoming' rather than 'being'. And since a bigger part of young people's lived experiences, mainly in industrialized countries and urban cities, is the frequent exposure and often daily use of a variety of media, it is of paramount importance to question and reflect on the process of socialization of twenty first century teenagers in the light of extensive use of new technologies and excessive use of internet.

In fact, in psychology and sociology scholars often describe socialization as a process whereby an individual learns the norms, values, behavior and social skill appropriate to one's social position. It also refers to the process by which young people acquire various patterns of cognitions and behaviors. Therefore, it is understood that the process of socialization is never ending as it begins at the earlier years of a person's life and continues till their last breath, but the most influencing periods, in this process, are childhood and adolescence where the person is most receptive during these growing years of life. When investigating how socialization takes place in the individual's social life, psychologists acknowledge the crucial role that family, culture, school and peer groups play in influencing the pattern of socialization in children and teenagers. However, in the late twentieth century and beginning of the new millennium, another factor has emerged as a more powerful agent and influencing variable affecting the socialization of a child. It is the internet and its virtual world. In many parts of the world, internet has a growing influence on children as children often take the rescue of their virtual self as defense mechanism to satisfy their innate needs [26].

In the same token, recently psychologists have added a new facet to the most modern form of socialization. It is technology socialization. Have coined that technology socialization is accomplished via personal experience to a large extent especially when the internet usage is specific, such as for entertainment or communication of information search. As for 21st century teenagers and children in the biggest part of the world, they are so much exposed to internet as they have grown up in an environment pervaded by advanced technologies. Lindstrom \& Seybold [27] state that today's children are as comfortable being online as they are when offline. Nowadays, because of an overabundance of social media sites, teenagers and children have a virtual presence in sites like Facebook, snapchat, skype, whatsapp and others. This, I contend, schizophrenizes teenagers and makes them live a dual/double life.

Also, and according to the PEW Research Center, 77\% of teen social media users agree that people are less authentic and real when they log in to social media. Therefore, it is of high importance to question how young people view virtual relationships on social media. For instance, in terms of Facebook relationships, one might be texting someone, trying to get to know them, and then once they meet them in real life, they find out that they are a completely different person. A common misconception among social media users is that social media, and Facebook in particular, allow people to befriend others as if they were real people. That part of the teenagers' life, and therefore identity, is constructed in a virtual and unreal world shaped by unreal relationships certainly affect their other real part and identity.

It is in this sense and from this perspective that educators and parents, i.e. adults, who find it difficult to understand and communicate with younger people, need to dive into this hidden part of teens' life. The first aspect that grown-up people must grasp is the fact that today's teenagers of 10 to 18 years old belong to the digital natives' generation. Even in developing countries where technological advancements are still at their embryonic stage, an important number of teenagers do have the opportunity to own electronic devices and get access to internet at an early age. This makes of them a generation of people who have been born into a world that is digital where electronic devices represent their first language they speak and think in. However, there are those less privileged young people in the same community who were not born into this world. These are the digital immigrants who may be familiar with new technologies, but this came later in their life. So, it is decisive to know if the youngster is a digital native or digital immigrant when we want to understand deeply his or her behavior based on his or her relationship with and dependence on internet/new technologies.

One major difference between digital natives and digital immigrants is that digital natives create information and information in turn creates/shapes them. They live in a culture which is mediated. Their identities are mediated by a constant stream of information coming from a wide range of sources. Virtual activity enables these young people to experiment with different personas. Moreover, and more importantly, for digital natives, the mass of their information is often not obtained in schools or libraries but rather from virtual settings like instant messaging, e-mailing friends, visiting social networking websites, blogs and wikis. Even the nature of the information obtained in the virtual world is distinct. To explain further, Nicholas Carr [28], the author of The Shallow: What the Internet is Doing to our Brains, argues that the net is making us more superficial 
as thinkers due to a perpetual and constant distraction. This permanent and constant distraction, by moving so fast from website to website and by looking for so many information in a short time, does affect the way digital natives think, so instead of a linear thinking, theirs is rather a more fragmented type of reasoning. This fact is completely denied or ignored by older people, those who are digital immigrants or even digital outsiders. Thus, it has become imperative for parents, educators and young people themselves to understand what is going on and happening in schools, streets and societies worldwide. To decipher and comprehend the behavior of young people which has been profoundly affected by extensive use of internet and new technologies, parents and educators must leap into action, and one of the ways to do that could be offered by netnographers. As it has been mentioned previously in this article, netnography is used to study the phenomenon of online sociability - a result of the online exchange of information.

It is argued that there is a free behavior on social media in the sense that people express honestly their perceptions and frank opinions. This may provide researchers with much data that can be followed over the long-term, and it may also enable netnographers to follow and quantify changes over time by using analytic tools and methods to generate insights. Just as ethnographic research includes an analysis of communication patterns and content within the online social contexts, this activity is also a netnographic technique of analysis. According to Kozinets [29], "these social groups have a 'real' existence for their participants, and thus have consequential effects on many aspects of behavior, including consumer behavior." As a matter of fact, netnography is uniquely positioned among social media research methods to generate cultural insights from contextualized data rather than quantified data.

In this respect, educational institutions may need netnogaphers to do research on their students. If netnographers are given access to the accounts of social media or even platforms where students interact virtually, they would gather as much data as they can. These data would be then analyzed thoroughly and systematically. As such, netnographers would explore how the virtual socialization process affects the behavior of teenagers by tracing their online conversations, comments, statuses posted on their timelines and even the emojis they use [30,31]. As for the emoticons, these are recognized and processed by the brain as nonverbal information, which mean we read them as emotional communication, not words. Therefore, netnographers could trace the use of emojis, and other virtual interaction tools to understand the way teenagers develop their virtual emotional intelligence, and how the latter deeply affects the young people's relationships with real people, mainly parents and teachers.

It might seem unfeasible and impractical to extract data from students' social media accounts as these may be viewed as fake and falsified. However, recent research has theorized that social media profiles say a lot about people's personalities.
Joseph Cilona, a Manhattan-based licensed clinical psychologist, relationship expert and social media gur says: "Although [Facebook] is still in its infancy, research into social media is beginning to illuminate strong and significant relationships between personality and online behavior," She adds: "Most of the existing research indicates a strong correlation between various aspects of self-concept and self-esteem to online behavior." Therefore, profile picture choice, emojis' use, new timeline posts and statuses or tweets can be significant for netnographers to investigate online/offline behavior of youngsters [32-34]. Observing teenagers online is not always possible since they may not befriend elder people on social media or may not allow them to see everything they post on their accounts. As a matter of fact, the netnographers' mission to explore the hidden and virtual life of young people may not always be successful, and yet netnographers may ask for the consent of institution or the social media network itself to be allowed to access the teenagers' profiles.

Another possibility for netnographers to observe and get data on teenagers' online behavior is academic and learning platforms like edmodo. Here, it is the role of the teacher to get the students register and log in the website regularly so that the netnographer would trace their activity online. And although the edmodo and other educational platforms are more formal so the online behavior of youngsters is restricted, netnographers could make interesting observations on the way youngsters interact with their teachers both virtually and formally. These observations could be extended to the classroom to see the difference between online teacher-student interactions and inclass teacher-student interactions.

To recapitulate, the extensive use of new technologies and the constant online presence by young people made it impossible to deny the deep fusion between our virtual interactions and our real life. Unarguably, the latter has had a drastic impact on the way people communicate with each other because nowadays technology has become an integral part of the way that people communicate with one another. More importantly, virtual communications have increasingly taken the place of faceto-face interactions mainly among young people around the globe, and now many grown-up individuals fear that younger generations may be too immersed in this digital world and not present enough in the real world. This might not be as fearful as the fact that older people will not be able to communicate with their youngsters anymore. So instead of rejecting the new way younger generation communicates through, they must understand the deeply-rooted changes that are taking place, and they must comprehend these changes.

One effective method for understanding how the virtualization of young people's life is affecting their social life is netnography. The latter would serve in observing the online behavior of young people to decipher eventually offline behavior and interactions. In the present paper, I aimed at exposing the 
relevance and significance of the role that netnographers could play in educational institutions. This research, though it lacks a case study through which results could have been validated, is a good initiative to think of new emerging fields in the humanities that look closely at the strong influence of the digitalization of our life. This article proposes that netnographers should be hired in educational institutions to explore the online behavior of students with the aim of analyzing and interpret it. It is this analysis and/or interpretation that might help educators and parents understand better their young people and wellcommunicate with them accordingly.

\section{References}

1. Kozinets Robert V (1998) Book review of D. Owram's Born at the Right Time, Historical Journal of Film, Radio and Television. 18(3) 455-457.

2. Schreibman S, Siemens R, Unsworth J (2018) A Companion to Digital Humanities. Blackwell Publishing. Malden, MA, Oxford, and Carlton, Blackwell Publishing, Victoria, UK, pp. 28-611.

3. Steven E Jones (2013) The Emergence of the Digital Humanities London, Routledge, UK

4. Alvarado R (2011) The Digital Humanities Situation. The Transducer.

5. Taporwiki (2011) How do you define Humanities Computing/Digital Humanities.

6. Matthew G Kirschenbaum (2010) What Is Digital Humanities and What's It Doing in English Departments? ADE Bulletin, pp. 150.

7. Terras Melissa, Nyhan Julianne, Vanhoutte Julianne (2013) Defining Digital Humanities: A Reader. Ashgate Publishing Limited, Farnham, UK.

8. Escobar A (1994) Welcome to Cyberia. Notes on the anthropology of cyberculture. Current Anthropology, 35(3): 211-231.

9. Godelier Maurice (1971) Salt Currency' and the Circulation of Commodities Among the Baruya of New Guinea. In Studies in Economic Anthropology. George Dalton (Eds.), American Anthropological Association, Washington DC, USA, p. 52-73.

10. Pfaffenberger B (1992) Social anthropology of technology. Annu Rev Anthropol 21: 491-516.

11. Wilson SM, Peterson LC (2002) The Anthropology of Online Communities. Annual Review of Anthropology, 31: 449-467.

12. Heather A Horst, Daniel Miller (2012) Digital Anthropology Bloomsbury Academic.

13. Miller D (2018) Digital Anthropology. In the Cambridge Encyclopedia of Anthropology. Stein F, Lazar S, Candea M, Diemberger H, Robbins J, Sanchez A, Stasch R (Eds.), London, UK.

14. Vaast E, Walsham G (2013) Grounded theorizing for electronicallymediated social contexts. European Journal of Information Systems 22(1): 9-25

15. Medberg G, Heinonen K (2014) Invisible value formation: a netnography in retail banking. International Journal of Bank Marketing, 32(6): 590607.
16. Mkono M, Ruhanen L, Markwell K (2015) From netnography to autoethnography in tourism studies. Annals of Tourism Research, 52: 167-169.

17. Kozinets Robert V (2002) The Field Behind the Screen: Using Netnography for Marketing Research in Online Communities. Journal of Marketing Research, 39: 61-72.

18. Kozinets Robert V (2010) Netnography: Doing Ethnographic Research Online, Sage, London, UK.

19. Ferreira Cátia (2015) Exploring Virtual Worlds: Conducting a Netnographic Research in Second Life, Estudos em Comunicação no 18: $35-59$

20. Hine C (2000) Virtual Ethnography. Sage, London, UK.

21. Kozinets Robert V (2012) Marketing Netnography: Prom/ot(ulgat)ing a New Research Method. Methodological Innovations Online (MIO), $7(1): 37-45$.

22. Bengry Howell A, Wiles R, Nind M, Crow G (2011) A Review of the Academic Impact of Three Methodological Innovations: Netnography, Child-Led Research and Creative Research Methods. National Centre for Research Methods.

23. Kozinets Robert V (2012) Me/my research/avatar. Journal of Business Research, 65: 478-482.

24.Zemmels D (2012) Youth and new media: Studying identity and meaning in an evolving media environment. Communication Research Trends, 31: 4 .

25. Maslow AH (1943) A theory of human motivation. Psychological Review, 50(4): 370-396.

26. Bhatt Megha, Bhatt Yogendra (2015) Internet as Influencing Variable in Child's Socialization: A Review International. Journal of Computer Science and Mobile Computing, 4(4): 75-80.

27. Lindstrom Martin, Patricia B Seybold (2003) BRAND child: Insights into the Minds of Today's Global Kids: Understanding Their Relationship with Brands. Kogan Page Ltd. London, UK.

28. Carr Nicholas (2010) The Shallow: What the Internet is Doing to our Brains. New York, USA.

29. Robert V Kozinets, Daiane Scaraboto, Marie Agnès (2018) Parmentier Journal of Marketing Management. 34: 3-4.

30. Braidotti R (2011) Nomadic Theory: The Portable Rosi Braidotti. Columbia University Press, New York, USA.

31. Giardiello Patricia (2018) Youth identities: Media discourse in the formation of youth identity. Language, Identity and Symbolic Culture eds David Evans, Bloomsbury academic, UK.

32. Haraway, Donna Jeanne (1991) A Cyborg Manifesto: Science, Technology, and Socialist-Feminism in the Late Twentieth Century. Simians, Cyborgs and Women: The Reinvention of Nature. Routledge, UK.

33. Sherry Turkle (2012) Alone Together: Why We Expect More from Technology and. Less From Each Other. Basic Books, New York, USA.

34. Lindstrom Martin, Patricia B Seybold (2003) BRAND child: Insights into the Minds of Today's Global Kids: Understanding Their Relationship with Brands, Kogan Page Ltd. London, UK. 


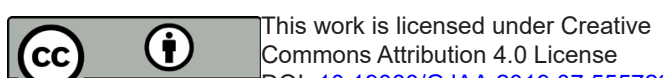

(CC) Commons Attribution 4.0 License

\section{Your next submission with Juniper Publishers} will reach you the below assets

- Quality Editorial service

- Swift Peer Review

- Reprints availability

- E-prints Service

- Manuscript Podcast for convenient understanding

- Global attainment for your research

- Manuscript accessibility in different formats

( Pdf, E-pub, Full Text, Audio)

- Unceasing customer service

Track the below URL for one-step submission https://juniperpublishers.com/online-submission.php 